\title{
Lexical Configuration in Adhan: A Semantic Perspective
}

\author{
Mostafa Shahiditabar \\ Imam Sadiq (a.s.) University \\ M_shahidi2005@yahoo.com \\ Mohammad Amin Mozaheb \\ Imam Sadiq (a.s.) Uinversity \\ Mozaheb.ma@gmail.com
}

\begin{abstract}
Adhan is defined as the Islamic call for announcing the time of Salah (practice of formal worship in Islam) which is recited by muezzin at mosques. This study aims to explore adhan from a lexical configuration point of view which has been introduced by English linguist Cruse (1986). As an initial step, lexical configuration of Cruse (1986) is explained from lexical semantic point of view. Hierarchy, then is defined which is a set of elements related to one another in a characteristic way according to Cruse (1986). After elaborating on hierarchical chain of meaning in lexical semantics, the adhan text with transliteration and English meaning is provided. Analyzing adhan from the semantic view point of Cruse (1986) confirms that adhan is the symbol of Islamic belief and ideology. It is not a static chain of words but a dynamic melody that invites people to move to worship Allah. It also reports that worshipping Allah needs a movement toward Him and also moving toward Allah needs The Facilitator or the Leader who is aware of the howness of the moving that can show Allah's order and path to people. The Facilitator is Prophet Mohammad (P. B. U. H.) who shows the path of Salvation and Good Deeds. Based on Islamic philosophy, one can reach to Allah by means of Salah. Also, one will reach to Allah by doing what Allah says. This study also introduces a new hierarchy to broaden the lexical configuration proposed by Cruse (1986) as circular hierarchy.
\end{abstract}

Keywords: semantics; lexical configuration, hierarchy, adhan (azan), circular hierarchy

\section{Introduction}

The adhān (Arabic pronunciation [?æ'ðæ:n]), or Azan (Turkish pronunciation ['?æ:zæ:n] and Persian pronunciation ['?æzæ:n] or other possible dictations and pronunciations) is very common in Turkey, Azerbaijan, Iran, Afghanistan, Pakistan and some other countries. It is the Islamic call to announce the time of Salah, recited by the adhan teller (muezzin) at prescribed times of each day to summon Muslims for prayers (Salah [Arabic] or Namaz [Turkish and Persian]).

With regard to etymology, the root of adhan is 'dn (Arabic أَذَن [?e'đn]) meaning 'to permit' or udun, meaning 'ear'. In the history of Islam, adhan is called out by the adhan teller in the mosque three or five times a day (three times in Iran or five times in Saudi Arabia for example), traditionally and commonly from a minaret. Many purposes are mentioned for adhan but one of the main reasons embarking upon the multiple loud pronouncements of adhan in every mosque is to show and announce a comprehensible symbolic summary of Islamic belief and ideology to the hearer.

\section{Review of Literature}

A review of literature shows that Islamic ideology has been considered from a linguistics point of view, at least by Tavanaei, \& Saneipur, (2009), Nasiri, (2009), Yadollahpour, (2009).

Tavanaei \& Saneipur (2009) discussed about applying parsing rules to discover the cohesion of the text of the holy Qur'an. They divided verses of Qur'an into the minor portions according to parsing rules and concluded that there is cohesion in Qur'an's text. Nasiri (2009) studies the conceptual domain of Donya (world) in Qur'an from a semantic point of view. This paper also deals with the conceptual of apprised and renounced Donya and its relation to the conceptual domain of Qur'an. Yadollahpour (2009) tried to fix the meaning of human dignity in the discourse of the holy Qur'an with a semantic approach. Among these works, none has investigated a semantic analysis of adhan.

Different aspects of adhan as the symbol of Islamic ideology and belief have been taken into consideration by Muslims. One of the aspects of adhan is its reciting by adhan teller. The adhan teller is the most notable person in the mosque in 
prayer time since he (not she) is chosen for his talent and ability in reciting the adhan beautifully and loudly for Muslims. Many adhan tellers have tried to recite adhan in the best way like Rahim Moazzen Zadeh Ardabili, Toghi and Galvash among others. As far as the review of the literature is concerned, no linguistic or specifically semantic analysis of adhan has been carried out so far, and this study is believed to be the first study of the mentioned domain. In other words, this study aims to consider adhan from a semantic point of view. More specifically this study strikes to answer the following research questions:

1. How adhan is in accordance with the hierarchy series introduced by Cruse (1986)?

2. What is the central concept of adhan according to lexical configuration?

3. What are some implications of adhan according to lexical configuration?

\section{Method}

Cruse (1986) introduces two types of lexical configurations, namely, hierarchies and proportional series in his seminal work. He categorizes hierarchies into taxonomic hierarchies, part-whole hierarchies and non-branching hierarchies and proportional series into doublets and cluster (for detailed consideration see Cruse (1986)).

Hierarchy is a group of elements related to one another in a characteristic way. In the case of hierarchies, two structural types of hierarchies can be distinguished according to Cruse (1986): those with branch, and those which are not capable of branching, because of the nature of their constitutive relations. Cruse (1986) depicts this classification as the following:

Table1. Cruse (1986)'s hierarchies (p.12).

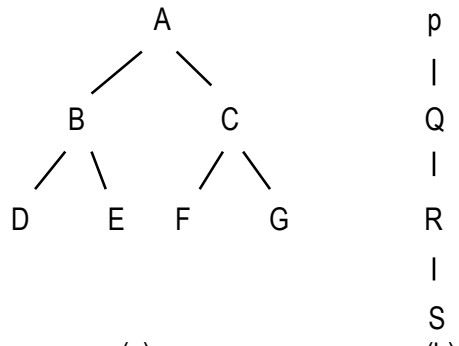

(a)

(b)

Cruse (1986) points out that relation of dominance is the most fundamental structural relation of any hierarchy, adding that without relation of dominance we do not have any hierarchy at all. In other words, relation of dominance is the vertical relation in the hierarchy. According to the above picture, the relation which connects $A$ to $C$ and $B, C$ to $G$ and $F$, and $B$ to $E$ and $D$ in (a), and $P$ to $Q, Q$ to $R$ and $R$ to $S$ is what Cruse (1986) calls vertical relation.

In addition to vertical relation, a relation of difference is seen in (a) as well. This is called horizontal relation by Cruse (1986) which holds between $C$ and $D, G$ and F, and $E$ and $D$ in (a).

Cruse (1986) also speaks about a well-formed hierarchy and requirements of a possible hierarchy. He declares that "in a well-formed hierarchy, the relation of dominance and relation of difference are constant through the structure." He also points out that "the minimum requirement for a hierarchy is a set of interrelated elements structured by a suitable relation acting as a relation of dominance," believing that two properties are essential for the relation of dominance of a hierarchy, namely, symmetric and asymmetric.

One of the other concepts that is defined in lexical configuration is 'level' which is shown in the following table by Cruse (1986). 
Table 2. Levels in lexical configurations by Cruse (1986, p.12)

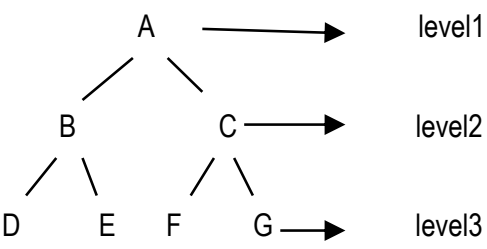

According to Cruse (1986), each element of a hierarchy occurs at a particular level. In this study, adhan is going to be explored according to one of the most complex types of lexical configurations, namely, hierarchy introduced by Cruse (1986).

Adhan as defined earlier is the Islamic call to announce the time for praying recited by the adhan tellers at prescribed times of each day to summon Muslims for prayers. Adhan (in Shia belief) and its meaning, transliteration and translation are presented in the following table:

Table 3. Adhan (in Shia belief) and its transliteration and translation

\begin{tabular}{|c|c|c|c|}
\hline Recital & Arabic & Transliteration & Translation \\
\hline $4 x$ & الله اكبر & Allahu Akbar & Allah is great. \\
\hline $2 x$ & اشهذ ان لا اله الا الله & Ash-had an-la ilāha illa llah & I testify that there is no deity except Allah. \\
\hline $2 x$ & 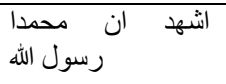 & $\begin{array}{l}\text { Ash-hadu anna Muhammadar- } \\
\text { rasūlu llāh }\end{array}$ & $\begin{array}{l}\text { I testify that Muhammad (P.B.U.H.) is the } \\
\text { Messenger of Allah. }\end{array}$ \\
\hline $2 x$ & اشهذ ان عليا ولي الله & Ash-hadu anna Aliyan wali-ul-lah & $\begin{array}{l}\text { I testify that Ali (P.B.U.H.) is the vicegerent (wali) } \\
\text { of Allah. }\end{array}$ \\
\hline $2 x$ & حي على الصلاة & Hayya 'alas-salāh & Hasten to Pray (salah). \\
\hline $2 x$ & حي على الفلاح & Hayya 'alal-falāh & Hasten to Salvation. \\
\hline $2 x$ & حي على خير العمل & Hayya- al Khair al amal & Hasten to the Best deeds. \\
\hline $2 x$ & الله اكبر & Allah-u Akbar & Allah is great. \\
\hline $2 x$ & لا لاله الا الله & Lā ilāha illallāh & There is no deity except Allah \\
\hline
\end{tabular}

\section{Hierarchies}

According to Cruse (1986, p. 12), a hierarchy is defined as the following manner, "a hierarchy, which need not consist of lexical items, is a set of elements related to one another in a characteristic way."

For analyzing adhan in a characteristic way, its meaning is given, and then it is shown in the hierarchy. 
Table 4. Meanings of different lines of adhan

\begin{tabular}{|c|c|c|c|c|}
\hline \multicolumn{2}{|l|}{ Adhan } & \multicolumn{2}{|l|}{ Meaning } & $\begin{array}{l}\text { Central } \\
\text { Concept }\end{array}$ \\
\hline Allahu Akbar & $\stackrel{-----\longrightarrow}{\longrightarrow}$ & Allah is great. & $\stackrel{-\cdots+---\longrightarrow}{\longrightarrow}$ & Allah \\
\hline Ash-had an-la ilāha illa llah & $\stackrel{----\longrightarrow}{\longrightarrow}$ & $\begin{array}{l}\text { I testify that there is no deity } \\
\text { except Allah. }\end{array}$ & $\stackrel{-----\longrightarrow}{\longrightarrow}$ & Allah \\
\hline $\begin{array}{l}\text { Ash-hadu anna Muhammadar- } \\
\text { rasūlu llāh }\end{array}$ & $\stackrel{-----\rightarrow}{\longrightarrow}$ & $\begin{array}{l}\text { I testify that Muhammad (P.B.U.H.) } \\
\text { is the Messenger of Allah. }\end{array}$ & $------\longrightarrow$ & Prophet \\
\hline Ash-hadu anna Aliyan wali-ul-lah & $\stackrel{----\longrightarrow}{\longrightarrow}$ & $\begin{array}{l}\text { I testify that Ali (P.B.U.H.) is the } \\
\text { vicegerent (wali) of Allah. }\end{array}$ & $\stackrel{-----\longrightarrow}{\longrightarrow}$ & Vicegerent \\
\hline Hayya 'alas-salāh & $\stackrel{----\longrightarrow}{\longrightarrow}$ & Hasten to Pray (salah). & $\stackrel{----\longrightarrow}{\longrightarrow}$ & Salah \\
\hline Hayya 'alal-falāh & $\stackrel{----\longrightarrow}{\longrightarrow}$ & Hasten to success. & $\stackrel{----\longrightarrow}{\longrightarrow}$ & Salvation \\
\hline Hayya- al Khair al amal & $\stackrel{----\longrightarrow}{\longrightarrow}$ & Hasten to the Best deeds. & $\stackrel{----\longrightarrow}{\longrightarrow}$ & Best deeds \\
\hline Allah-u Akbar & $\stackrel{----\longrightarrow}{\longrightarrow}$ & Allah is great. & $\stackrel{-----\longrightarrow}{\longrightarrow}$ & Allah \\
\hline
\end{tabular}

\section{Results}

As it is seen in the above table, adhan starts with the name of Allah. Then Allah's name represents in another lexical form. It follows Prophet Mohammad (P.B.U.H)'s name and his name follows Imam Ali (P.B.U.H)'s name. Calling people to say their prayers (Salah or Namaz) and speaking about Salvation and Best Deeds which are related to praying, are next steps of adhan. At the end, again the name of Allah (God) is told two times. Summary of adhan is shown in the following:

Table 5. Summary of adhan

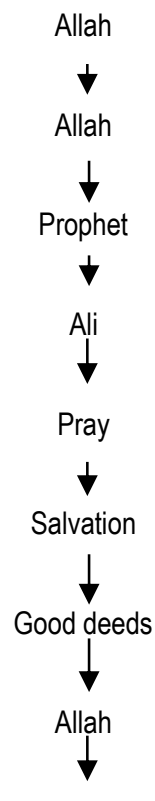

Allah 
As it is seen in the above hierarchy, four central levels are obvious in adhan: level 1: Allah, level 2: Prophet Muhammad (P.B.U.H.) and Imam Ali (P.B.U.H) (Allah's Agent), level 3: Pray, Salvation and Good Deeds (Pray related words = Allah's order) and level 4: Allah. Now, the mentioned levels are shown in the following table.

Table 6. Different levels in adhan

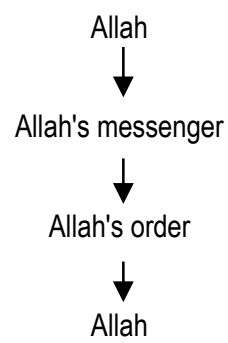

A glance at the above-presented hierarchy shows that adhan starts with Allah and ends in Allah. Also, the central lexicon of all elements of adhan is Allah. But there seems to be a problem with the hierarchy. Allah has dominance over Allah's messenger and Allah's messenger dominates Allah's order, but Allah's order does not dominate Allah but it cannot be seen in the above hierarchy.

The authors believe that this problem can be solved by proposing a new type of hierarchy. The researchers of the present study recommend a 'circular hierarchy' as the solution to find out the internal configuration of adhan as it is shown below.

Figure 1. Circular hierarchy of adhan

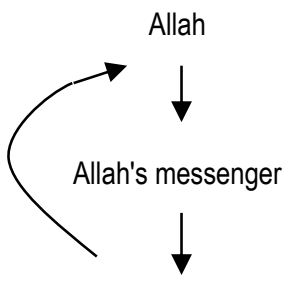

Allah's order

The above-shown circular is shown in a better way as the following:

Figure 2. Full-scale circular hierarchy of adhan

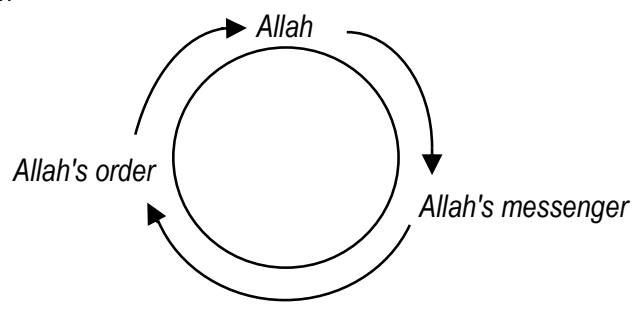

It can be proved that Allah is the starting and ending point of the hierarchy. In other words, Allah is linked to Allah's messenger, and Allah's messenger's dominance relates to dominance of Allah's order and Allah's order is connected to His dominance. 
If we accept the mentioned proposed hierarchy of adhan, then we can prove some facts about adhan. In the following paragraphs, the mentioned issues will be discussed in details.

With regard to the central concept of adhan, as far as the proposed hierarchy is concerned, Allah is the central concept of adhan. In other words, adhan starts with Allah and ends in Allah.

It is obvious that adhan contains three semantic domains. They are domain of Allah, domain of Allah's agent and domain of Salah or Allah's order. Allah as the central concept of adhan and Allah domain dominates not only the beginning and end of adhan, but also Allah's messenger and Allah's order domains. In other words, the main semantic lexicon of adhan is Allah.

The mentioned movement (circling of adhan) is also visible in its structure. To put it simply, circular hierarchy is implied from adhan's verbal structure. To explain this point, the verbs in each line of adhan will be presented in the following table.

Table 7. Explanation of verbs used in adhan

\begin{tabular}{|l|l|}
\hline Adhan & Type of Verb \\
\hline Allahu Akbar & Copula \\
\hline Ash-had an-la ilāha illa llah & Performative \\
\hline Ash-hadu anna Muhammadar-rasūlu llāh & Performative \\
\hline Ash-hadu anna Aliyan wali-ul-lah & Performative \\
\hline Hayya 'alas-salāh & Imperative \\
\hline Hayya 'alal-falāh & Imperative \\
\hline Hayya- al Khair al amal & Imperative \\
\hline Allah-u Akbar & Copula \\
\hline la ilāha illa llah & Copula \\
\hline
\end{tabular}

As it is seen in the table, adhan starts with copula in the first level. Next three levels of adhan have performative utterances (the verb Ash-hadu). Performative utterances are followed by imperatives, and adhan ends in two copulas as it is shown in the following figure according to circular hierarchy:

FFigure 3. Performative utterances and imperatives in adhan

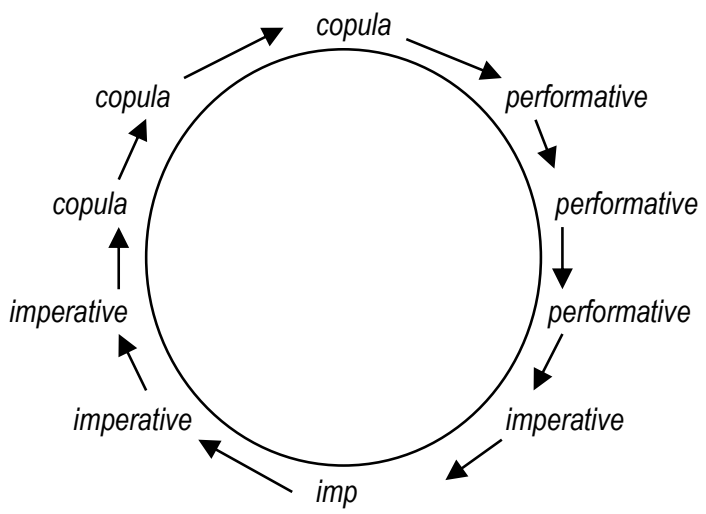

It can be pointed out that adhan is started with a copula verb but it changes to apply performative utterances and imperatives. 
As far as the speech act theory is concerned, an action is done in using performatibe utterances. In other words, when a Muslim says Ash-hadu anna Muhammadar-rasūlu llāh, he does an action that is to testify that Muhammad (P.B.U.H.) is the Messenger of Allah.

Imperatives are located after performative utterances in adhan. In imperatives' level of adhan, a Muslim is invited to act and hasten to Salah or Salvation or Good Deeds. It means that there is a need to consider imperatives that is assigned from Allah that should be done by Muslims. In other words, there seems to be movement (both verbal movement (performative utterances) and physical movement (imperatives)) in adhan.

Briefly summarized, the analysis of the verbs in adhan shows that adhan as the symbol of Islamic belief, is not a static prose but a dynamic melody that invites people to move towards Allah. The other point is that moving towards Allah needs a facilitator to show Allah's order or path. The facilitators are Prophet Mohammad (P.B.U.H.) and Imam Ali (P.B.U.H.) that demonstrate the path of Salvation and Good Deeds.

\section{Introducing a noble hierarchy of lexical configuration}

As mentioned earlier, Cruse (1986) introduces two types of lexical configurations namely, hierarchies and proportional series in his seminal work, lexical semantics. He categorizes hierarchies into taxonomic hierarchies, part-whole hierarchies and non-branching hierarchies and proportional series into doublets and cluster. A new hierarchy is seen in this study that is called circular hierarchy. It is believed that this new hierarchy could be added to Cruse (1986)'s hierarchies. The hierarchies have been presented below.

Figure 4. Cruse (1986)'s hierarchies and the new hierarchy put forth in the current study<smiles>[2H]B(F)CC(O)F</smiles>

$$
\begin{aligned}
& p \\
& \mid \\
& Q \\
& I \\
& R \\
& I \\
& S
\end{aligned}
$$

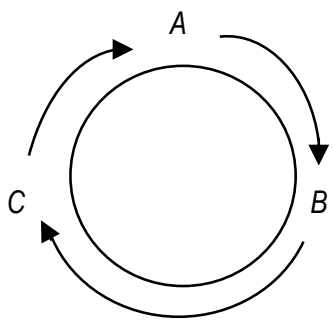

As it is seen in the above categorization, in circular hierarchy, an element is a central concept in the hierarchy that is $A$ in the picture. In circular hierarchy, the central concept has domination over the whole hierarchy and also the central concept or member of the hierarchy is located in the beginning and ending part of the circle of the hierarchy. It is also possible to say that the central concept is located in the middle of the hierarchy and the other elements are going around the circle as it is shown in the following way:

Figure 5. Demonstration of circular hierarchy

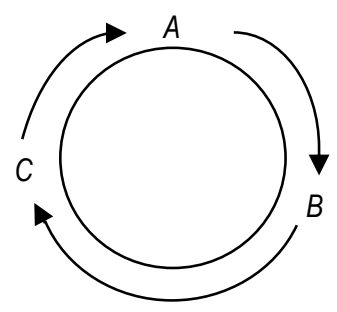




\section{Conclusion}

With regard to the first question 'How adhan is in accordance with the hierarchy series introduced by Cruse (1986)?' it can be mentioned that adhan is not completely in accordance with the hierarchy series introduced by Cruse (1986), since according to adhan Allah has dominance over Allah's messenger and Allah's messenger dominates Allah's order while Allah's order does not dominate Allah. The mentioned points cannot be seen completely in hierarchy series introduced by Cruse (1986) and a finer scale is introduced by the authors of the present study to answer the mentioned shortcoming. Regarding the second research question, 'What is the central concept of adhan according to lexical configuration?', it can be said that Allah is the central concept of adhan according to lexical configuration. Considering the third question of the study, 'What are some implications of adhan according to lexical configuration?' it is conceivable that adhan is a dynamic melody that invites people to move towards Allah by showing Allah's path that is Salah. As far as adhan is concerned, moving towards Allah needs a facilitator that is Allah's messengers who are Prophet Muhammad (P.B.U.H.) and Imam Ali (P.B.U.H).

\section{Dedication}

To Prophet Muhammad (P. B. U. H.).

\section{Acknowledgements}

We are greatly indebted to Dr. Akbar Shahiditabar for his constructive comments.

\section{References}

[1] Coseriu, E. (1975). Vers une typologie des champs lexicaux. Cahiers de Lexicologie, 27, 30-51.

[2] Cruse, D. A. (1986). Lexical Semantics. Cambridge. Cambridge University Press.

[3] Geckeler, H. (1971). Strukturelle semantik und wortfeldtheorie. Munich: Fink

[4] Johnson, M. (1987). The body in the mind: The bodily basis of meaning, imagination and reason. Chicago: Chicago University Press.

[5] Lehrer, A. J. (1974). Semantic fields and lexical structure. Amsterdam. North Holland .

[6] Lutzeier, P. R. (1981). Wort und feld. Tubingen: Max Niemeyer Verlag.

[7] Lutzeier, P. R. (1983). The relevance of semantic relation between words for the notion of lexical field, Theoretical Linguistics, 10, 147-178.

[8] Miller, G. A. \& Johnson-Laird, P. N. (1967). Language and perception. Cambridge: Cambridge University Press.

[9] Nasiri, R. (2009). Donya in Holy Quran: A semantic study. Quarterly of Quranic Science and Culture, 2.

[10] Rasekh Mahnd, M. (2011). An introduction to cognitive linguistics: Theories and concepts. Tehran: SAMT.

[11] Searle, J. R. (1975). The taxonomy of illocutionary acts. In Günderson, K (ed.). Language, mind, and knowledge. Minneapolis.

[12] Safavi, K. (2009). An introduction to semantics. Tehran: Soore Mehr Publication.

[13] Tavanaei, M. H., \& Saneipur, M. H. (2009). Constituents of Quran. Quarterly of Quranic Science and Culture. 2.

[14] Trier, J. (1934). Das sprachliche feld. Eine Auseinandersetzung. Neue Jahrbucher fur Wissenschaft und Jugenbildung, 10, 428-49 .

[15] Yadollahpour, B. (2009). Semantics of human dignity in the conceptual system of the Holy Quran. Quarterly of Quranic Science and Culture. 2.

\section{Biographical notes}

Mostafa Shahiditabar is an instructor of Linguistics. He is a faculty member at Imam Sadiq (P.B.U.H.) University and has published on various topics in Linguistics in several international journals. He has also presented papers in professional conferences. His research interests include discourse analysis, child language acquisition, semantics and Turkish linguistic. Mohammad Amin Mozaheb is a PHD candidate in Applied Linguistics. He is a faculty member at Imam Sadiq (P.B.U.H.) University. His papers appeared in several national and international journals. His research interests cover discourse analysis and writing. 